\title{
Synthesis and study of aroylethyl(ethyl)-xanthates as stabilizers of polymeric materials
}

\author{
Tanzila Akchurina ${ }^{1} \cdot$ Sabira Sardarova ${ }^{1} \cdot$ Khuraman Efendiyeva $^{1} \cdot$ Irada Eyvazova $^{1} \cdot$ Vagif Farzaliyev $^{1}$. \\ Afsun Sujayev ${ }^{1}$ (D)
}

Received: 9 May 2021 / Accepted: 5 September 2021 / Published online: 14 September 2021

(c) The Author(s) 2021

\begin{abstract}
The number of aroylethyl (ethyl)xanthates have been synthesized by the reaction of the exchange decomposition of $\beta$-dimethylaminopropiophenone hydrochlorides with potassium xanthate containing several functional groups $(\mathrm{C}=\mathrm{O}, \mathrm{C}=\mathrm{S}$, $\mathrm{C}-\mathrm{OH}$ ), which determine the use of these xanthates as stabilizers with internal synergy to polymeric materials. It was shown that the thermal stability of the compounds, depending on the nature of the substituent in the benzene ring of the molecule was observed in the temperature range of $149-196^{\circ} \mathrm{C}$. It was revealed that aroylethyl(ethyl)xanthates had a stabilizing effect due to the suppression of thermo-oxidative destruction of polyethylene; they increased the induction period of polyethylene oxidation by 2-6 times, and the oxidation rate was reduced by about 3-9 times. Among the studied compounds, 4-hydroxybenzoylethyl (ethyl)xanthate had the greatest stabilizing effect. The study of the mechanism of the stabilizing action of the compounds showed that xanthates react with cumene hydroperoxide (CHP), which proceeded through the stage of formation of an intermediate product that actively decomposed CHP, i.e., the oxidation chain was terminated by the decomposition of the CHP not by the initial xanthates but by their transformation products.
\end{abstract}

Keywords Synthesis $\cdot$ Aroylethyl (ethyl)xanthate $\cdot$ Thermal stability $\cdot$ Polyethylene stabilizers $\cdot$ Mechanism of action

\section{Introduction}

As stabilizers prevent degradation of polymers, it is inevitable to give a brief overview on the degradation of polymers before discussing the mechanism of action of stabilizers. Performance is one of the biggest factors to determine the choice for a stabilizer system. Besides the performance, there are many other factors that determine the choice for a stabilizer system. As stabilizers have to protect polymers for long times, it is important that these stabilizers stay in a polymer over the lifetime, which is related to several stabilizer-related physical factors. Stabilizers are normally added in mixtures or together with other additives; possible interaction between these additives might have an influence on the performance of stabilizers. Reactions with other chemicals from the environment of the plastic can lead to a deactivation of the stabilizer and a reduced lifetime. In many

Afsun Sujayev

s.afsun@mail.ru

1 Institute of Chemistry of Additives, ANAS, Baku 1029, Azerbaijan cases, another requirement for stabilizers is that they are not colored or discolored. If polymers are used that can come into contact with food, an indirect food contact approval is required. As stabilizers have to be added to a polymer there are requirements for toxicity and disability $[1,2]$.

In connection with the increased operational requirements for polymeric materials and products [3, 4], it became necessary to develop effective and thermally resistant stabilizers. For the directed synthesis of this type of stabilizers, it is of great importance to identify the limits of their resistance to high temperatures.

Additives are essential to make polymers processable and to assure their end-use properties. The demands on additives have continued to evolve, not only because of changes in processing conditions and production techniques but also because polymers are being used in more demanding applications $[5,6]$. This revised and updated edition, described earlier by one reviewer as the "bible" for anyone involved in the chemistry and technology of polymer additives, again provides an excellent overview of the complex science and technology of polymer additives and their industry. It offers guidance for all professionals involved in the development 
of new thermoplastic resin grades and novel end-use applications [4].

Derivatives of oxyaromatic ketones are compounds that can be used as polyolefin stabilizers [7].

Oxybenzophenone and its derivatives effectively protect polymers from light aging, and compounds containing sulfide sulfur from heat aging. On the other hand, alkaline xanthate, for example, potassium ethyl xanthate, is known as a heat stabilizer [8], but it is ineffective. The effectiveness of these compounds can be increased by the introduction of phenolic antioxidants $[9,10]$.

In this aspect, the synthesis and study of aroylethyl (ethyl) xanthates containing several functional groups, such as $\mathrm{C}=\mathrm{O}, \mathrm{C}=\mathrm{S}, \mathrm{C}-\mathrm{OH}$ and others, are of interest as stabilizers with internal synergism [11].

At the same time it is known that xanthates are not stable compounds and their decomposition generates $\mathrm{CS}_{2}$, a substance that is considered toxic. These aspects have motivated the search for that polymer additives performance without the health, safety and environmental concerns associated with xanthates.

In addition, the generation of $\mathrm{CS}_{2}$ is favored as time elapses and the $\mathrm{pH}$ of the solutions de-creases from 10 to 6 , regardless of the hydrocarbon chain length. Conversely, dithiophosphinate and hydroxamic acids present greater chemical stability, although they form micelles at a certain concentration, a phenomenon that is not observed with xanthates. By not hydrolyzing, oxidizing, or decomposing into other chemical species, this compounds may be considered environmentally friendly reagents. In the above context, it is important to promote the adoption of these additives in polymer processing.

\section{Material and methods}

\section{Measurements}

The chemical structure of the synthesized compounds (1-8) was confirmed using ${ }^{1} \mathrm{H},{ }^{13} \mathrm{C}$ NMR spectra. NMR experiments have been performed on a Bruker FT NMR spectrometer AVANCE $300\left(300 \mathrm{MHz}\right.$ for ${ }^{1} \mathrm{H}$ and $75 \mathrm{MHz}$ for ${ }^{13} \mathrm{C}$ ) with BVT 3200 variable-temperature unit in $5 \mathrm{~mm}$ sample tubes using Bruker Standard software (Topspin 3.1). The ${ }^{1} \mathrm{H}$ and ${ }^{13} \mathrm{C}$ chemical shifts were referenced to internal tetramethylsilane (TMS). NMR grade DMSO- $d_{6}(99.7 \%$, containing $0.3 \% \mathrm{H}_{2} \mathrm{O}$ ), $\mathrm{CDCl}_{3}$ and $\mathrm{C}_{6} \mathrm{D}_{6}$ was used for the synthesized compounds. All spectra are given in Supporting Information (SI).

The preparation of $\beta$-dimethylaminopropiophenone hydrochlorides used in this work was described earlier [8]. $\beta$-dimethylamino-4-nitropropiophenone hydrochloride (M.P. $186^{\circ} \mathrm{C}$ ) was also obtained as described in the literature.
IR spectra of the synthesized compounds were recorded on IRS-10 spectrometer in the frequency range of $400-4000 \mathrm{~cm}^{-1}$ ( $\mathrm{KBr}$ pellets or films). The studies were carried out in a microlayer and in $\mathrm{CCl}_{4}$ solution $\left(5 \times 10^{-3} \mathrm{M}\right)$.

The $(\mathrm{C}, \mathrm{H}, \mathrm{N}, \mathrm{S})$ microanalyses were performed on a Flash EA 1112 CHNS-O/MAS (CHN Analyzer) instrument. Melting points (uncorrected) were determined with melting point SMP3 (Stuart Scientific).

Aroylethyl (ethyl) xanthates can be identified through optical absorption peaks in the infrared $(1179,1160,1115$, $\left.1085 \mathrm{~cm}^{-1}\right)$ and ultraviolet $(300 \mathrm{~nm})$ ranges. Iodometric method relies on oxidation to dixanthogen by iodine, with the product detected with a starch indicator. This method, however, is not selective and suffers from interferences with other sulfur-containing chemicals.

Xanthate can react with a copper sulfate or copper tartrate resulting in a copper xanthate residue which is detected with iodine. This method has an advantage of being insensitive to sulfite, thiosulfate and carbonate impurities.

In the acid-base detection method, a dilute aqueous xanthate solution is reacted with a copious amount of $0.01 \mathrm{M}$ hydrochloric acid yielding carbon disulfide and alcohol, which are evaluated. The excess acid and impurities are removed through filtering and titration.

Thermoanalytical studies of aroylethyl (ethyl) xanthates were carried out on OD-102 T derivatograph of the Paulik system (Hungary) in a dynamic heating mode with a heating rate of $5{ }^{\circ} \mathrm{C} / \mathrm{min}$. A weighed portion of a sample was $50 \mathrm{mg}$; calcined alumina served as a standard.

The single-valued parameters of thermogravimetric analysis (TGA) data were used as criteria for assessing the stability of the studied compounds against temperature influences, i.e. there are accepted temperatures corresponding to equal fractions of their mass loss with increasing temperature, determined on TGA data, for example, $T_{10 \%}, T_{50 \%}$; as well as the corresponding differential thermogravimetry (DTG) and differential thermal analysis (DTA) parameters. The thermal stability of the studied esters was also characterized by the temperature range of their thermochemical transformations, which makes it possible to more fully judge the possible performance of the compounds as polymer materials stabilizers in the given temperature conditions. The temperature at the beginning of the interval of thermochemical transformations corresponded to $5 \%$ of the weight loss of the sample from the initial sample, and the temperature of the end of this interval was determined at the point where the DTA and DTG data reached the baseline.

The thermal stability of the studied xanthates was evaluated by the temperatures at which the weight loss made 5\% $\left(T_{5 \%}\right)$.

Studies of the interaction of the synthesized xanthates with CHP were also carried out by thermal analysis. The 
xanthate:CHP ratio in thermoanalytical experiments ranged from $1: 1$ to $1: 5$.

The study of the synthesized compounds as polyethylene aging stabilizers was carried out according to the following procedure. The studied compounds, in a ratio of 0.5 wt $\%$, were mixed with polyethylene П-2006-B this purpose the studied compounds were dissolved in acetone and added with stirring to the calculated amount of powdered polyethylene. After evaporation of acetone and drying of the obtained mass in an oven at room temperature, a sample weight $(1 \mathrm{~g})$ was taken.

Thermooxidation of the stabilized polyethylene was carried out in Gaiman apparatus at $160{ }^{\circ} \mathrm{C}$ and a pressure of $200 \mathrm{mmHg}$ in oxygen atmosphere. The effect of thermal oxidation of the studied compounds was determined by a change in the induction period of polyethylene oxidation subject to decrease in oxygen pressure.

\section{Experimental}

Benzoylethyl(ethyl)xanthate (comp. 1): a mixture of $7.5 \mathrm{~g}$ of potassium ethylxanthate (PEX) and $10 \mathrm{~g}$ of $\beta$-dimethylaminopropiophenone in $50 \mathrm{ml}$ of alcohol (70 $\mathrm{wt} \%$ in water) were stirred for $5 \mathrm{~h}$ at $70{ }^{\circ} \mathrm{C}$. The separated product was filtered off, washed with water, and after repeated re-crystallization a crystalline substance (M.P. $92{ }^{\circ} \mathrm{C}$ ) was obtained.

${ }^{1} \mathrm{H}$ NMR (300 MHz, DMSO- $\left.d_{6}, \delta\right) 1.11\left(\mathrm{t}, 3 \mathrm{H}, \mathrm{CH}_{3}\right)$, $3.57\left(\mathrm{~d}, 2 \mathrm{H}, \mathrm{CH}_{2}\right), 3.06\left(\mathrm{~d}, 2 \mathrm{H}, \mathrm{CH}_{2}(-\mathrm{S}-\mathrm{C}-\mathrm{R})\right), 3.22(2 \mathrm{H}$, $\left.\mathrm{CH}_{2}(-\mathrm{C}(=\mathrm{O}))\right), 7.52,7.63,7.95(\mathrm{~m}, \mathrm{H}, \mathrm{Ar}) .{ }^{13} \mathrm{C}$ NMR (75 MHz, DMSO-d 6 , ठ) 14, 31.9, 40.6, 62.3, 128.7, 128.8, 133.2, 136.7, $200.1(\mathrm{C}=\mathrm{O}), 215.3(\mathrm{C}=\mathrm{S})$.

The other aroylethyl (ethyl) xanthates were obtained similarly:

4-Methylbenzoylethyl (ethyl) xanthate (comp.2): by the interaction of $17.5 \mathrm{~g}$ of PEX and $25 \mathrm{~g}$ of $\beta$-dimethylamino4-methylpropiophenone hydrochloride;

${ }^{1} \mathrm{H}$ NMR $\left(300 \mathrm{MHz}, \mathrm{CDCl}_{3}, \delta\right) 1.01$ (t, 3H, $\left.\mathrm{CH}_{3}\right), 2.41$ (s, $\left.3 \mathrm{H}, \mathrm{CH}_{3}\right), 3.52\left(\mathrm{~d}, 2 \mathrm{H}, \mathrm{CH}_{2}\right), 3.08$ (d, 2H, $\mathrm{CH}_{2}(-\mathrm{S}-\mathrm{C}-\mathrm{R})$ ), $3.12\left(2 \mathrm{H}, \mathrm{CH}_{2}(-\mathrm{C}(=\mathrm{O}))\right), 6.78,7.41(\mathrm{~m}, \mathrm{H}, \mathrm{Ar}) .{ }^{13} \mathrm{C} \mathrm{NMR}$ (75 MHz, $\left.\mathrm{CDCl}_{3}, \delta\right)$ 14.5, 24.3, 32, 41, 62, 128.7, 128.9, 134, 142.8, $201(\mathrm{C}=\mathrm{O}), 215(\mathrm{C}=\mathrm{S})$.

4-Methoxybenzoylethyl (ethyl)xanthate (comp.3): by the interaction of $7.5 \mathrm{~g}$ of PEX and $10 \mathrm{~g}$ of $\beta$-dimethylamino4-methoxypropiophenone hydrochloride;

${ }^{1} \mathrm{H}$ NMR $\left(300 \mathrm{MHz}, \mathrm{CDCl}_{3}, \delta\right) 1.09\left(\mathrm{t}, 3 \mathrm{H}, \mathrm{CH}_{3}\right)$, 3.85 (s, 3H, $\left.\mathrm{CH}_{3}-\mathrm{O}-\right), 3.55\left(\mathrm{~d}, 2 \mathrm{H}, \mathrm{CH}_{2}\right), 3.03(\mathrm{~d}, 2 \mathrm{H}$, $\left.\mathrm{CH}_{2}(-\mathrm{S}-\mathrm{C}-\mathrm{R})\right), 3.32\left(2 \mathrm{H}, \mathrm{CH}_{2}(-\mathrm{C}(=\mathrm{O}))\right), 7.02,7.95$ (m, $\mathrm{H}, \mathrm{Ar}) .{ }^{13} \mathrm{C}$ NMR $\left(75 \mathrm{MHz}, \mathrm{DMSO}-\mathrm{d}_{6}, \delta\right) 14.3,31.9,40.6$, $55.8,62.4,114.2,129.8,165,142.8,203(\mathrm{C}=\mathrm{O}), 216(\mathrm{C}=\mathrm{S})$.

4-Hydroxybenzoylethyl(ethyl)xanthate (comp.4): by the interaction of $9.7 \mathrm{~g}$ of PEX and $14 \mathrm{~g}$ of $\beta$-dimethylamino4-hydroxypropiophenone hydrochloride;
${ }^{1} \mathrm{H}$ NMR (300 MHz, $\left.\mathrm{C}_{6} \mathrm{D}_{6}, \delta\right) 1.03\left(\mathrm{t}, 3 \mathrm{H}, \mathrm{CH}_{3}\right), 3.57$ (d, 2H, $\left.\mathrm{CH}_{2}\right), 3.07$ (d, 2H, $\left.\mathrm{CH}_{2}(-\mathrm{S}-\mathrm{C}-\mathrm{R})\right), 3.21(2 \mathrm{H}$, $\left.\mathrm{CH}_{2}(-\mathrm{C}(=\mathrm{O}))\right), 6.81,7.87$ (m, H, Ar), $9.83(\mathrm{~d}, 1 \mathrm{H}, \mathrm{OH}-\mathrm{Ph})$. ${ }^{13} \mathrm{C}$ NMR (75 MHz, DMSO-d 6 , $\left.\delta\right) 14,31,40,62,115.8$, $129.3,130.2(-\mathrm{C}(=\mathrm{O})-\mathrm{C}), 162.9,200(\mathrm{C}=\mathrm{O}), 214(\mathrm{C}=\mathrm{S})$.

4-Bromobenzoylethyl(ethyl)xanthate (comp.5): by the interaction of $7.5 \mathrm{~g}$ of PEX and $10 \mathrm{~g}$ of $\beta$-dimethylamino-4bromopropiophenone hydrochloride;

${ }^{1} \mathrm{H}$ NMR (300 MHz, DMSO- $\left.d_{6}, \delta\right) 1.05\left(\mathrm{t}, 3 \mathrm{H}, \mathrm{CH}_{3}\right)$, $3.53\left(\mathrm{~d}, 2 \mathrm{H}, \mathrm{CH}_{2}\right), 3.03\left(\mathrm{~d}, 2 \mathrm{H}, \mathrm{CH}_{2}(-\mathrm{S}-\mathrm{C}-\mathrm{R})\right), 3.16(2 \mathrm{H}$, $\left.\mathrm{CH}_{2}(-\mathrm{C}(=\mathrm{O}))\right), 7.75,7.98(\mathrm{~m}, \mathrm{H}, \mathrm{Ar}) .{ }^{13} \mathrm{C}$ NMR $(75 \mathrm{MHz}$, DMSO-d $\left._{6}, \delta\right)$ 14.3, 31.5, 40.4, 62.2, 127.5, 131.0, 131.5, 135.7, $200.2(\mathrm{C}=\mathrm{O}), 215.5(\mathrm{C}=\mathrm{S})$.

2-Hydroxy-5-methylbenzoylethyl (ethyl) xanthate (comp.6): by the interaction of $10 \mathrm{~g}$ of PEX and $15 \mathrm{~g}$ of $\beta$-dimethylamino-2-hydroxy-5-methylpropiophenone hydrochloride;

${ }^{1} \mathrm{H}$ NMR (300 MHz, DMSO- $\left.d_{6}, \delta\right) 1.07\left(\mathrm{t}, 3 \mathrm{H}, \mathrm{CH}_{3}\right)$, $2.35\left(\mathrm{~m}, 3 \mathrm{H}, \mathrm{CH}_{3}-\mathrm{Ph}\right), 3.51\left(\mathrm{~d}, 2 \mathrm{H}, \mathrm{CH}_{2}\right), 3.05(\mathrm{~d}, 2 \mathrm{H}$, $\left.\mathrm{CH}_{2}(-\mathrm{S}-\mathrm{C}-\mathrm{R})\right), 3.20\left(2 \mathrm{H}, \mathrm{CH}_{2}(-\mathrm{C}(=\mathrm{O}))\right), 6.69,7.07,7.52$ (m, H, Ar), $9.83(\mathrm{~d}, 1 \mathrm{H}, \mathrm{OH}) .{ }^{13} \mathrm{C}$ NMR $(75 \mathrm{MHz}$, DMSO$\left.\mathrm{d}_{6}, \delta\right) 14.0,24.3,31.9,40.43,62.3,115.7,121.7,130.4$, $130.9,131.5,134.8,157.7,200(\mathrm{C}=\mathrm{O}), 215.1(\mathrm{C}=\mathrm{S})$.

2-Hydroxy-5-chlorobenzoylethyl (ethyl)xanthate (comp.7): by the interaction of $4.8 \mathrm{~g}$ of PEX and $8 \mathrm{~g}$ of $\beta$-dimethylamino-2-hydroxy-5-chloropropiophenone hydrochloride;

${ }^{1} \mathrm{H}$ NMR $\left(300 \mathrm{MHz}\right.$, DMSO- $\left.d_{6}, \delta\right) 1.05\left(\mathrm{t}, 3 \mathrm{H}, \mathrm{CH}_{3}\right)$, 3. $54\left(\mathrm{~d}, 2 \mathrm{H}, \mathrm{CH}_{2}\right), 3.01\left(\mathrm{~d}, 2 \mathrm{H}, \mathrm{CH}_{2}(-\mathrm{S}-\mathrm{C}-\mathrm{R})\right), 3.21(2 \mathrm{H}$, $\left.\mathrm{CH}_{2}(-\mathrm{C}(=\mathrm{O}))\right), 6.75,7.28,7.73(\mathrm{~m}, \mathrm{H}, \mathrm{Ar}), 9.78(\mathrm{~d}, 1 \mathrm{H}$, $\mathrm{OH}) .{ }^{13} \mathrm{C}$ NMR $\left(75 \mathrm{MHz}, \mathrm{DMSO}_{-} \mathrm{d}_{6}, \delta\right) 14.0,32,40,62$, $117.2,121.7,123.2,126.8,130.2,134.6,158.8,200(\mathrm{C}=\mathrm{O})$, $215(\mathrm{C}=\mathrm{S})$.

4-Nitrobenzoylethyl (ethyl) xanthate (comp.8): by the interaction of $7.5 \mathrm{~g}$ of PEX and $12 \mathrm{~g}$ of $\beta$-dimethylamino-4nitropropiophenone hydrochloride.

${ }^{1} \mathrm{H}$ NMR $\left(300 \mathrm{MHz}, \mathrm{DMSO}-d_{6}, \delta\right) 1.08\left(\mathrm{t}, 3 \mathrm{H}, \mathrm{CH}_{3}\right), 3$. $52\left(\mathrm{~d}, 2 \mathrm{H}, \mathrm{CH}_{2}\right), 3.06\left(\mathrm{~d}, 2 \mathrm{H}, \mathrm{CH}_{2}(-\mathrm{S}-\mathrm{C}=\mathrm{R})\right), 3.24(2 \mathrm{H}$, $\left.\mathrm{CH}_{2}(-\mathrm{C}(=\mathrm{O}))\right), 8.15,8.27$ (m, H, Ar). ${ }^{13} \mathrm{C}$ NMR $(75 \mathrm{MHz}$, DMSO-d $\left.{ }_{6}, \delta\right) 14,31.9,40.6,62.3,117.2,121.7,123.8$, 129.7, 142.8, 152.3, $200.1(\mathrm{C}=\mathrm{O}), 215.3(\mathrm{C}=\mathrm{S})$.

\section{Results and discussion}

The article presents the results of synthesis and studies of thermal stability, stabilizing efficiency, as well as some aspects of the mechanism of action of a number of aroylethyl(ethyl)xanthates (1-8) obtained by the reaction of exchange decomposition of $\beta$-dimethylaminopropiophenone hydrochlorides with potassium xanthate according to the Scheme 1. 
$\mathrm{ArCOCH}_{2} \mathrm{CH}_{2} \mathrm{~N}\left(\mathrm{CH}_{3}\right)_{2} \cdot \mathrm{HCl}+\mathrm{C}_{2} \mathrm{H}_{5} \mathrm{OC}(\mathrm{S}) \mathrm{SK} \rightarrow \mathrm{ArCOCH}_{2} \mathrm{CH}_{2} \mathrm{SC}(\mathrm{S}) \mathrm{OC}_{2} \mathrm{H}_{5}$

Scheme 1 Synthesis of aroylethyl (ethyl) xanthates (1-8)

The obtained aroylethyl (ethyl) xanthates (see Table 1) are crystalline substances, readily soluble in acetone, alcohol, toluene, and insoluble in water. The composition and structure of aroylethyl (ethyl) xanthates (1-8) were confirmed by elemental analysis and IR spectra.

According to modern data, the inhibiting effect of oxidation inhibitors on the oxidation process of hydrocarbons consists in the termination of oxidation chains carried out through the interaction of antioxidants or their conversion products with intermediate oxidation products-peroxide radicals and hydroperoxides. The reactions of oxidation inhibitors with intermediate products of hydrocarbon oxidation are widely used as model reactions in studying the mechanism of their antioxidant action.

The most notable feature of the mechanism of the antioxidant action of previously studied such effective oxidation inhibitors as substituted oxyaryl sulfides is their ability to catalytically decompose hydroperoxides. Therefore, the aim of this work was to study the questions of the mechanism of decomposition of cumyl hydroperoxide by synthesized aroylethyl (ethyl) xanthates.

In the spectra of com. 1-8 in the $1644-1690 \mathrm{~cm}^{-1}$ region there is an absorption band characteristic for the stretching vibrations of the carbonyl group attached to the aromatic ring. A broad absorption band, in the 3360-2900 $\mathrm{cm}^{-1}$ region (comp. 2), characterizes the stretching vibrations of the hydroxyl group involved in the intermolecular hydrogen bond. In the case of com.6 and 7, this absorption band shifts to the $3100-2600 \mathrm{~cm}^{-1}$ region and does not change when using dilute solutions in carbon tetrachloride, which is explained by the presence of a relatively strong intramolecular hydrogen bond (IHB) in these compounds. The formation of IHB in these compounds also significantly reduces the frequency of stretching vibrations of the carbonyl group $\left(\gamma_{\mathrm{C}=\mathrm{O}} 1635 \mathrm{~cm}^{-1}\right)$. The absorption band in the $860-800 \mathrm{~cm}^{-1}$ region characterizes 1,4-substituted (com. 2-5, 8), and two absorption bands in the $820-800$ and $900-860 \mathrm{~cm}^{-1}$ regions describe 1,2,4-substituted benzene ring (com. 6, 7). It is known that stretching vibrations of the $\mathrm{C}-\mathrm{S}$ bond appear in the form of bands of weak intensity in the $600-800 \mathrm{~cm}^{-1}$ region [12]. However, in the case of the studied aroylethyl (ethyl) xanthates, the total effect of electrons (the mutual influence of the $s$ - and $p$-electron pairs of the $\mathrm{C}=\mathrm{S}$ group) shifts this band to the $580-595 \mathrm{~cm}^{-1}$ region. In the $1100-1200 \mathrm{~cm}^{-1}$ region there are absorption bands of stretching vibrations of the $\mathrm{C}-\mathrm{S}$ bond.

When synthesizing organic compounds proposed as potential stabilizers for polymeric materials, along with other operational properties, one should also take into account the need to ensure thermal stability of the stabilizers, which

Table 1 Characteristics of aroylethyl(ethyl)xanthates (1-8) with the general formula of<smiles>[R2]c1cc([R])c(C(=O)CC[SiH2][GeH2]CC)cc1[R2]</smiles>

\begin{tabular}{|c|c|c|c|c|c|c|c|c|c|c|c|c|}
\hline \multirow[t]{3}{*}{ № } & \multirow[t]{3}{*}{$\mathrm{R}$} & \multirow[t]{3}{*}{$\mathrm{R}_{1}$} & \multirow[t]{3}{*}{$\mathrm{R}_{2}$} & \multirow{3}{*}{$\begin{array}{l}\text { Yield } \\
\%\end{array}$} & \multirow[t]{3}{*}{$\mathrm{M} \cdot \mathrm{P}^{\circ} \mathrm{C}$} & \multirow{3}{*}{$\begin{array}{l}\text { M } \\
\text { (exp.) }\end{array}$} & \multicolumn{6}{|c|}{ Elemental composition, \% } \\
\hline & & & & & & & \multicolumn{3}{|l|}{ Found } & \multicolumn{3}{|c|}{ Calculated } \\
\hline & & & & & & & $\mathrm{C}$ & $\mathrm{H}$ & $\mathrm{S}$ & $\mathrm{C}$ & $\mathrm{H}$ & S \\
\hline 1 & $\mathrm{H}$ & $\mathrm{H}$ & $\mathrm{H}$ & 65 & 92 & 252 & 56.57 & 5.48 & 25.16 & 56.74 & 5.55 & 25.24 \\
\hline 2 & $\mathrm{CH}_{3}$ & $\mathrm{H}$ & $\mathrm{H}$ & 71 & 120 & 263 & 58.22 & 6.11 & 23.80 & 58.25 & 6.01 & 23.92 \\
\hline 3 & $\mathrm{OCH}_{3}$ & $\mathrm{H}$ & $\mathrm{H}$ & 82 & 97 & 280 & 55.02 & 5.64 & 22.48 & 54.97 & 5.07 & 22.55 \\
\hline 4 & $\mathrm{OH}$ & $\mathrm{H}$ & $\mathrm{H}$ & 78 & 143 & 273 & 53.42 & 5.12 & 23.66 & 53.77 & 5.22 & 23.74 \\
\hline 5 & $\mathrm{Br}$ & $\mathrm{H}$ & $\mathrm{H}$ & 56 & 155 & 329 & 43.40 & 3.42 & - & 43.27 & 3.33 & - \\
\hline 6 & $\mathrm{H}$ & $\mathrm{OH}$ & $\mathrm{CH}_{3}$ & 35 & 141 & 288 & 54.89 & 5.68 & 22.52 & 54.97 & 5.67 & 22.57 \\
\hline 7 & $\mathrm{H}$ & $\mathrm{OH}$ & $\mathrm{Cl}$ & 42 & 156 & 300 & 48.30 & 4.20 & - & 48.16 & 4.35 & - \\
\hline 8 & $\mathrm{NO}_{2}$ & $\mathrm{H}$ & $\mathrm{H}$ & 43 & 104 & 303 & 44.35 & 3.66 & 21.50 & 44.52 & 3.71 & 21.44 \\
\hline
\end{tabular}


allows them to operate in the required temperature conditions. In this regard, studies were carried out to identify the regularities linking the thermal stability of xanthates with their composition and structure, which was of interest in terms of predicting the optimal composition and structure of stabilizers with specified temperature properties.

Some data on thermochemical transformations of xanthates are given in Table 2. As can be seen from the table the thermal stability of the studied compounds lies within the temperature range of $149-196^{\circ} \mathrm{C}$.

A review of the parameters of thermal stability of the studied xanthates, depending on their composition and structure, showed that their stability under conditions of elevated temperatures depended on the nature and position of heteroatoms and functional groups in the benzene ring of the molecule.

As follows from the data of thermal studies, the introduction of a methyl radical, chlorine and bromine atoms, as well as functional groups such as methoxy-, hydroxyl-, or nitro- groups, leads to some decrease in the thermal stability of the corresponding derivatives of benzoylethyl(ethyl)xanthate. For example, the decomposition temperature $\left(\mathrm{T}_{5 \%}\right)$ of com. 3, 4, 8 (see Table 2) containing methoxy-, hydroxyl- or nitro- groups was 174,155 , and $149^{\circ} \mathrm{C}$, respectively, versus $196{ }^{\circ} \mathrm{C}$ for benzoylethyl(ethyl)xanthate. (com.1). The study of the data of thermal analysis showed that with a further increase in temperature xanthates decomposed at different rates, and therefore the sequence in the series of temperature indicators of their thermochemical transformations slightly changed (see Table 2). Semi-destruction $\left(T_{50 \%}\right)$ of the studied xanthates was achieved at $208-295^{\circ} \mathrm{C}$.

The studies of the synthesized compounds as polyethylene aging stabilizers showed that aroylethyl(ethyl)xanthate increased the induction period of polyethylene oxidation approximately by 2-6 times. So, if unstabilized, polyethylene begins to oxidize after $15 \mathrm{~min}$, then with the addition of 0.5 mass\% of com.1, 7, 4 to it, the oxidation induction period increases to $30,45,90 \mathrm{~min}$, respectively.
The studied compounds had an effect on the oxidation rate too. The study of the kinetics of the oxidation process showed that the decrease in oxygen pressure for unstabilized polyethylene made $10 \mathrm{~mm} \mathrm{Hg}$ after $15 \mathrm{~min}$, whereas with the introduction of the studied compounds into polyethylene, the rate of its oxidation decreased. For example, for com.1, a decrease in oxygen pressure was observed after 50 , for com.7-after 80, for com.4-after $140 \mathrm{~min}$.

To solve some problems in the field of polymer oxidation in the presence of the synthesized compounds, their thermoanalytical studies were carried out in a mixture with CHP to obtain information on the mechanism of hydroperoxide decomposition by the studied xanthates.

DTA data of CHP mixtures, for example, with com.4 or com.1 in the ratio 1: 1 at temperatures of 25 or $30{ }^{\circ} \mathrm{C}$, an exothermic effect is recorded with a maximum at temperatures of 47 or $66^{\circ} \mathrm{C}$, respectively, and heat is released without changing the mass of the mixtures. Further, on the DTA data at temperatures of 60 or $97{ }^{\circ} \mathrm{C}$, respectively, the following exothermic effect is observed, accompanied by accelerated weight loss in a narrow temperature range. A further increase in temperature leads to multistage transformations of thermal decomposition products with a slower rate of weight loss and corresponding endothermic effects.

Analysis of the thermoanalytical data of mixtures of all synthesized compounds with CHP allowed us to conclude that the ongoing reaction of CHP with xanthate proceeds through the stage of the formation of some product (I exo effect without weight loss), which subsequently actively decomposes CHP (II exo effect).

Table 3 shows the data of thermal analysis of com. $4, \mathbf{1}$, CHP and mixtures of the indicated xanthates with CHP in a molar ratio from 1:1 to 1:5. Comparison of the data shows that a reaction proceeds between xanthate and CHP, since the parameters characterizing the process of thermal transformations of mixtures are much lower than for individual components of the mixture.
Table 2 Thermal stability of aroylethyl(ethyl)xanthates

\begin{tabular}{lllllllll}
\hline № & $\mathrm{R}$ & $\mathrm{R}_{1}$ & $\mathrm{R}_{2}$ & $T_{5 \%}$ & $T_{10 \%}$ & $T_{20 \%}$ & $T_{50 \%}$ & $\begin{array}{l}\text { Decomposition } \\
\text { temperature } \\
\text { range }\end{array}$ \\
& & & & & & & & \\
\hline 1 & & & & & & & & \\
2 & $\mathrm{H}$ & $\mathrm{H}$ & $\mathrm{H}$ & 196 & 220 & 249 & 283 & $196-450$ \\
3 & $\mathrm{CH}_{3}$ & $\mathrm{H}$ & $\mathrm{H}$ & 158 & 170 & 184 & 208 & $158-500$ \\
4 & $\mathrm{OCH}_{3}$ & $\mathrm{H}$ & $\mathrm{H}$ & 174 & 185 & 198 & 246 & $174-500$ \\
5 & $\mathrm{OH}$ & $\mathrm{H}$ & $\mathrm{H}$ & 155 & 170 & 177 & 210 & $155-500$ \\
6 & $\mathrm{Br}$ & $\mathrm{H}$ & $\mathrm{H}$ & 161 & 163 & 171 & 295 & $161-550$ \\
7 & $\mathrm{H}$ & $\mathrm{OH}$ & $\mathrm{CH}$ & 155 & 164 & 176 & 237 & $155-500$ \\
8 & $\mathrm{H}$ & $\mathrm{OH}$ & $\mathrm{CI}$ & 157 & 161 & 170 & 239 & $157-500$ \\
\hline & $\mathrm{NO}_{2}$ & $\mathrm{H}$ & $\mathrm{H}$ & 149 & 165 & 184 & 289 & $149-600$ \\
\hline
\end{tabular}


Table 3 Thermal analysis data for 4-hydroxybenzoylethyl(ethyl) xanthate (com. 4), benzoylethyl(ethyl)xanthate (com.1), CHP and their mixtures

\begin{tabular}{llll}
\hline Samples & $\begin{array}{l}\text { Starting decomposi- } \\
\text { tion temperature, }{ }^{\circ} \mathrm{C}\end{array}$ & $\begin{array}{l}\text { Accelerated decomposition } \\
\text { process }\end{array}$ \\
\cline { 3 - 4 } & & $\begin{array}{l}\text { Temperature } \\
\text { range, }{ }^{\circ} \mathrm{C}\end{array}$ & Weight loss, \% \\
\hline Com.4 & 155 & $170-210$ & 67 \\
Com.1 & 196 & $220-315$ & 70 \\
CHP & 120 & $150-195$ & 65 \\
Com.4:CHP & & & \\
$1: 1$ & 65 & $65-105$ & 25 \\
$1: 2$ & 55 & $50-90$ & 42 \\
$1: 3$ & 50 & $50-70$ & 65 \\
$1: 5$ & 50 & $50-60$ & 78 \\
Com.1:CHP & & & \\
$1: 1$ & 110 & $125-151$ & 30 \\
$1: 2$ & 105 & $115-125$ & 40 \\
$1: 3$ & 90 & $110-122$ & 45 \\
$1: 5$ & 85 & $105-120$ & 45 \\
\hline
\end{tabular}

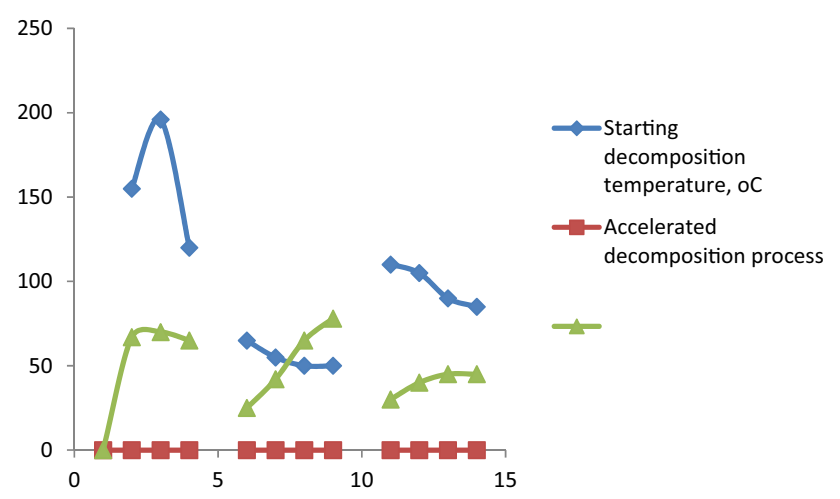

Fig. 1 Thermal analysis of compound 1 and 4

The study of thermoanalytical data showed that the chemical activity of com.4 in relation to CHP is significantly higher than com.1. Namely: com.4 actively decomposes hydroperoxide in the entire range of its concentration; in case of com.1, with an increase in the concentration of hydroperoxide, a decrease in the rate of its decomposition is observed, which also proceeds at a higher temperature; in addition, the weight loss due to the decomposition of CHP in a mixture with com.1, with an increase in CHP concentration, slightly increases only to a ratio of $1: 3$, a further increase in CHP concentration has no effect on weight loss. The results of thermoanalytical studies coordinate with the above data on the stabilizing efficiency of the synthesized xanthates (Table 3, Fig. 1).
At the same time in this study, the chemical stability of eight xanthates of different alkyl-, aryl groups (aroylethyl (ethyl) xanthates (1-8)) was evaluated by spectroscopy, as a function of $\mathrm{pH}$ and time. Similarly, the chemical stability of three chelating collectors was evaluated. Likewise, the surface tension of their aqueous solutions was measured making use of the Du Noy method, to determine the critical micelle concentration. The results showed that the xanthate absorption spectra reflect the presence of a chemical reaction as the $\mathrm{pH}$ decreases from 4 to 2.5 , which results in the formation of $\mathrm{CS}_{2}$.

\section{Conclusion}

By the interaction of $\beta$-dimethylaminopropiophenone hydrochlorides with potassium xanthate there has been synthesized a new series of compounds-aroylethyl (ethyl) xanthate as stabilizers for polymeric materials.

Thermoanalytical studies of aroylethyl(ethyl)xanthates (1-8) showed: the thermal stability of the studied compounds, depending on the nature and position of the substituent in the benzene ring of the molecule, lies within the temperature range of $149-196{ }^{\circ} \mathrm{C}$; Among the studied compounds, benzoylethyl(ethyl)xanthate (com.1) and p-methoxybenzoyl(ethyl)xanthate (com.3) have the highest thermal stability, the thermal stability of the other synthesized xanthates is within the range of $149-161^{\circ} \mathrm{C}$.

Thermal analysis data for mixtures of xanthates with CHP indicate a large weight loss proceeding at a high rate, which may indicate the catalytic decomposition of CHP by the studied xanthates.

The results of the studies of compounds as polymer stabilizers have shown that aroylethyl (ethyl) xanthates, having a stabilizing effect, prevent thermooxidative degradation of polyethylene. It was found that with the introduction of a hydroxyl group into the benzene ring of the xanthate molecule, the highest antioxidant efficiency of the compound was achieved; the induction period of polyethylene stabilized by it increased by 6 times, and the oxidation rate decreases by 9 times.

Thermoanalytical studies allowed to determine the chemical activity of aroylethyl (ethyl) xanthates as oxidation inhibitors in relation to CHP, i.e., to determine their comparative effectiveness as hydrogen peroxide breakers.

Thus, the synthesis and the results of studies to identify the dependence of the thermal stability of the studied aroylethyl (ethyl) xanthates on their composition and structure, as well as the study of their stabilizing properties and aspects of the mechanism of action, contribute to the creation of theoretical foundations for the directed synthesis of effective 
stabilizers of polymeric materials with predetermined temperature and functional properties.

Supplementary Information The online version contains supplementary material available at https://doi.org/10.1007/s13203-021-00281-z.

\section{Declarations}

Conflict of interest The authors declare that there are no conflicts of interest.

Open Access This article is licensed under a Creative Commons Attribution 4.0 International License, which permits use, sharing, adaptation, distribution and reproduction in any medium or format, as long as you give appropriate credit to the original author(s) and the source, provide a link to the Creative Commons licence, and indicate if changes were made. The images or other third party material in this article are included in the article's Creative Commons licence, unless indicated otherwise in a credit line to the material. If material is not included in the article's Creative Commons licence and your intended use is not permitted by statutory regulation or exceeds the permitted use, you will need to obtain permission directly from the copyright holder. To view a copy of this licence, visit http://creativecommons.org/licenses/by/4.0/.

\section{References}

1. Zweifel H, Maier R, Schiller M (2009) Plastics additives handbook 6E. Hanser Publications, Ohio, p 1248 (ISBN: 9781569904305)

2. Smith G, Hallett J, Joseph P et al (2017) Structural studies of thermally stable, combustion-resistant polymer composites. Polym J 49:711-719. https://doi.org/10.1038/pj.2017.44

3. Crompton TR (2012) Thermal stability of polymers. Smithers RAPRA, 226 pp. ISBN 9781847355140/. https://www.chemi stryworld.com/culture/thermal-stability-of-polymers/5543.article
4. Gijsman P (2011) Polymer stabilization. In: Applied plastics engineering handbook. William Andrew Publishing, Norwich, pp 375-399. https://doi.org/10.1016/B978-1-4377-3514-7.10021-2

5. Wypych G (2015) PVC degradation and stabilization, 3rd edn. ChemTec Publishing, pp 287-412. https://www.elsev ier.com/books/pvc-degradation-and-stabilization/wypych/ 978-1-895198-85-0

6. Wypych G (2015) PVC degradation and stabilization, 3rd edn. ChemTec Publishing, pp 79-165. https://www.elsev ier.com/books/pvc-degradation-and-stabilization/wypych/ 978-1-895198-85-0

7. Reingruber E, Buchberger W (2010) Analysis of polyolefin stabilizers and their degradation products. J Sep Sci 33(22):34633475. https://doi.org/10.1002/jssc.201000493

8. Kuliyev AM, Guseinov MS, Sardarova SA, Iskenderova TY (1972) Alkylation with Mannich bases. Synthesis and research of morpholino- piperazino derivatives of oxypropiophenones. J Org Chem 8(6):1301-1304

9. Pourreza N (2013) Phenolic compounds as potential antioxidant. Jundishapur J Nat Pharm Prod 8(4):149-150. https://doi.org/10. 17795/jjnpp-15380

10. Rubén San Miguel-Chávez (2017) Phenolic antioxidant capacity: a review of the state of the art. https://doi.org/10.5772/66897

11. Palaty S, Devi PV, Mary KJ (2010) Characterization and thermal decomposition behaviour of xanthate compounds. Prog Rubber Polimeres Recycl Technol 26(4):199-214. https://doi.org/10.1177/ 147776061002600404.i.n

12. Bellamy LJ (1958) The infra-red spectra of complex molecules. Methuen \& Co Ltd, London, p 433

Publisher's Note Springer Nature remains neutral with regard to jurisdictional claims in published maps and institutional affiliations. 